\title{
Biomarker concordance between molecular stereotactic biop- sy and open surgical specimens in gliomas
}

\author{
Jacek Furtak ${ }^{1}$, Maciej Mielczarek ${ }^{1}$, Mateusz Szylberg ${ }^{1}$, Maciej Harat ${ }^{2,3}$ \\ ${ }^{1}$ Department of Neurosurgery, $10^{\text {th }}$ Military Research Hospital, Bydgoszcz, Poland \\ ${ }^{2}$ Department of Oncology and Brachytherapy, Nicolaus Copernicus University, Ludwik Rydygier Collegium Medicum, Bydgoszcz, \\ Poland
}

${ }^{3}$ Unit of Radiosurgery and Radiotherapy of CNS Tumours, Department of Radiotherapy, Franciszek Lukaszczyk Memorial Oncology Centre, Bydgoszcz, Poland

\section{ABSTRACT}

Aims. To compare 1p/19q codeletion, MGMT promoter methylation, and IDH mutation status in stereotactic biopsy and open craniotomy specimens.

Clinical rationale. The latest WHO classification of gliomas requires assessment of the expression of molecular markers. Samples can be obtained for molecular assays via open craniotomy or molecular stereotactic biopsy (MSB). However, there is uncertainty as to whether MSB is representative of the entire tumour, and therefore how reliable it is for treatment planning.

Patients and methods. We examined 11 patients diagnosed with brain tumours suspicious of glioma who underwent open craniotomy after stereotactic biopsy and in whom multiple biomarkers were assessed in both sets of samples by methylation-specific multiplex ligation-dependent probe amplification. Institutional Review Board ethical approval was granted (KB 694/2018).

Results. The initial histopathological grade as determined by stereotactic biopsy was the same as in the samples obtained by open surgery. Further, the marker profile used here was valid in both high- and low-grade gliomas.

Conclusion and clinical implication. MSB is a reliable way to obtain material for precision medicine approaches.

Key words: 1p/19q codeletion; glioma; IDH; methylation-specific multiplex ligation-dependent probe amplification; MGMT; stereotactic biopsy

(Neurol Neurochir Pol 2019; 53 (6): 435-441)

\section{Introduction}

Gliomas are the most common primary malignant intracranial tumour, with an annual incidence of $\sim 5$ cases per 100,000 people [1-6]. In addition to the patient's performance status at the time of diagnosis, the main prognostic factor for glioma is the presence/absence of some common biomarkers: (i) methylation of the promoter of the gene encoding the enzyme O-6-methylguanine-DNA methyltransferase (MGMT); (ii) isocitrate dehydrogenase 1 (IDH1) mutations; (iii) isocitrate dehydrogenase 2 (IDH2) mutations; and (iv) chromosome $1 \mathrm{p} / 19 \mathrm{q}$ codeletion. These molecular tests are diagnostic, prognostic, clinical manifestations and, in some cases, predictive of responses to different therapies [7-11]. $I D H 1$ and $I D H 2$ mutations are useful in the assessment of primary and secondary gliomas and, if present, indicate at least WHO grade II glioma [12]. 1p/19q codeletion supports the diagnosis of oligodendroglioma/oligoastrocytoma [13, 14 ], occurring in $\sim 75 \%$ of oligodendrogliomas and $\sim 45 \%$ of oligoastrocytomas but seldom in fibrillary astrocytomas $(\sim 8 \%)[14,15]$. Molecular testing alters the diagnosis in about $3 \%$ of cases [16].

However, tumour heterogeneity may also influence the detection and value of these biomarkers [17]. 1p/19q deletions, 
MGMT methylation, and IDH mutations can all show heterogeneity in individual tumours, thereby limiting the routine implementation of these molecular results derived from biopsies in clinical practice [17].

\section{Clinical rationale}

Molecular stereotactic biopsy (MSB) of untreated gliomas may improve diagnostic precision and enable personalised treatment in inoperable patients. However, glioma heterogeneity and limited cell numbers in small MSB biopsy samples can give rise to diagnostic errors. Therefore, the aim of this study was to compare the molecular results derived from MSBs to those in open craniotomy specimens.

\section{Materials and methods}

\section{Patients, consent, and ethics}

The Department of Neurosurgery at the $10^{\text {th }}$ Military Research Hospital (Bydgoszcz, Poland) has conducted over 2,500 stereotactic biopsies of brain tumours since 1996. MSB has been performed since 2014 . Here, we retrospectively analysed data from a database of 485 patients undergoing MSB.

MSB was performed when: (1) primary tumours and recurrences were located within areas of increased risk of comorbidity without severe mass effect demanding debulking surgery because of brainstem compression and/or midline shift; (2) patients had Karnofsky performance status (KPS) $<60$; and (3) inflammation or lymphoma was suspected. Open craniotomy was performed after MSB when radiology and biopsy results were equivocal.

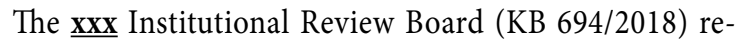
viewed and approved the study protocol, which was conducted according to the principles of the Declaration of Helsinki.

\section{Biopsy and surgery procedures}

CT brain scans were performed after fixation of the stereotactic frame to the head on the day of surgery. CT images were co-registered with preoperative MRI scans. Patients were consented and operated upon by a neurosurgeon who, based on the imaging results and clinical features, developed the biopsy trajectory using iPlan software (BrainLAB, Germany) (Fig. 1A). Biopsy needles were inserted, and serial samples were obtained every $1 \mathrm{~mm}$ using microforceps from contrastenhancing parts of the tumour.

For MSB, the first biopsy sample was stained with methylene blue for intraoperative histopathological examination. The neuropathologist classified samples according to the World Health Organisation (WHO) criteria [18]. Every second sample was taken for histopathology assessment and immunohistochemistry as necessary. The same sample was examined by methylation-specific (MS-) multiplex ligation-dependent probe amplification (MLPA) for molecular alterations (see below). The sample intraoperatively assessed as the largest (on average 50 cells) was selected for molecular testing.

During craniotomy, samples for molecular and histopathological assessment were chosen arbitrarily by the neurosurgeon based on macroscopic evaluation (e.g. highly vascularised areas), and radiological changes visualised by MRI used for neuronavigation $+/$ - application of 5-ALA fluorescence marker (Fig. 2). Tumour samples for postoperative molecular examination were much larger than those taken for intraoperative biopsy. After surgery, MRI was used to assess the resection status using a $3 \mathrm{~T}$ (Philips) device, $\mathrm{T} 1$ and $\mathrm{T} 2$ sequences, and after intravenous administration of gadobutrol contrast medium $(1 \mathrm{mmol} / \mathrm{ml}$ ) at a dose of $0.1 \mathrm{ml} / \mathrm{kg}$ body weight [19] (Fig. 1B).

\section{Molecular analysis}

MS-MLPA allows simultaneous analysis of multiple molecular markers using small amounts (100 ng) of DNA isolated

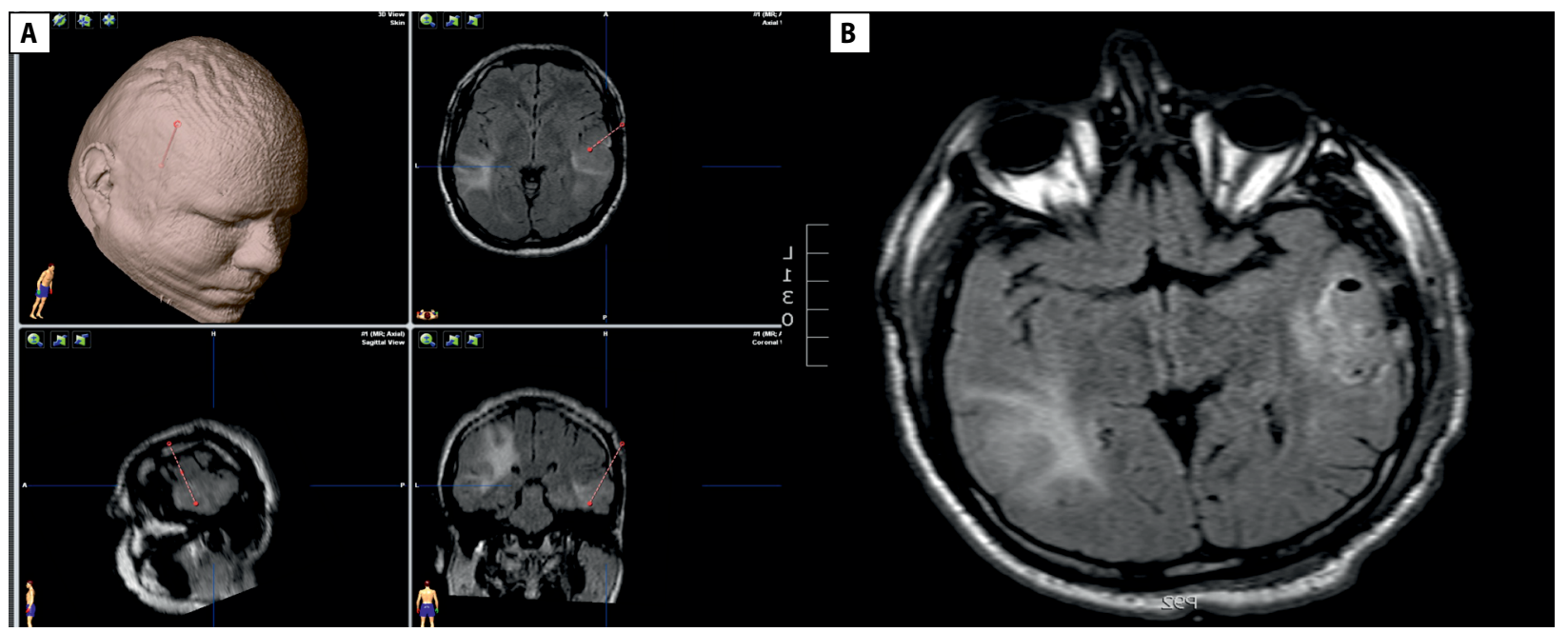

Figure 1. A. biopsy planning based on T2-Flair MRI (patient 2). B. Post surgery T2-Flair MRI (patient 2) 


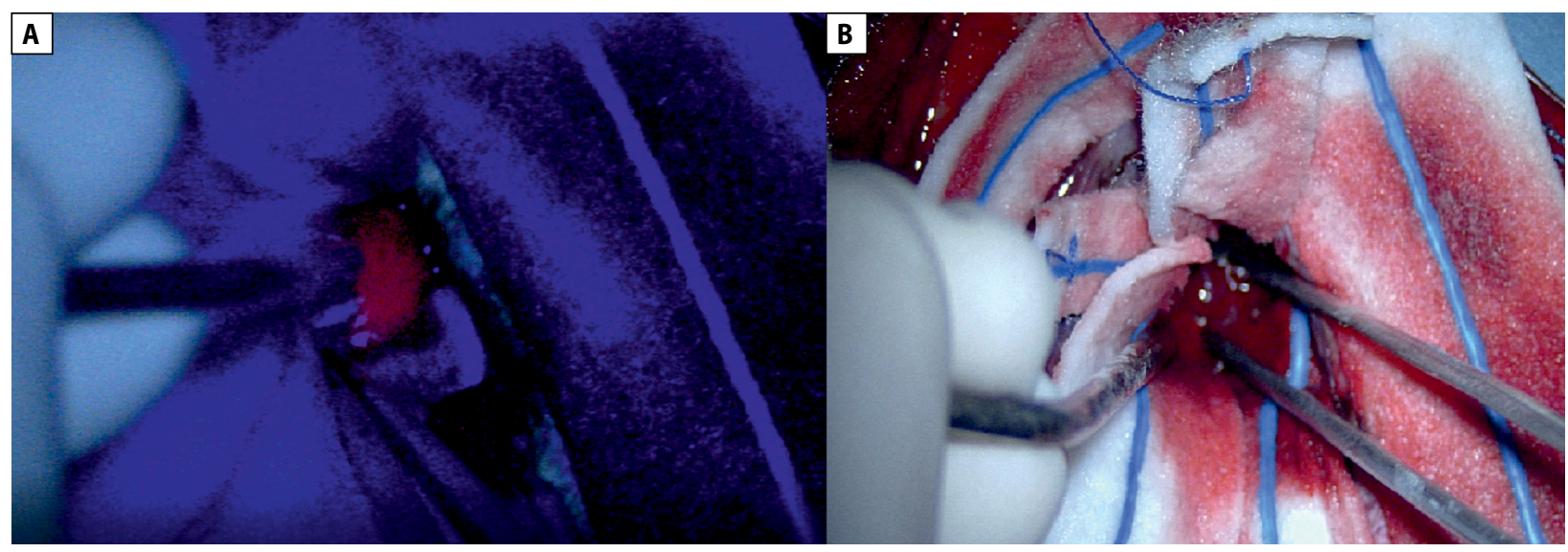

Figure 2. A. Tumour in 5-ALA induced fluorescence (patient 9). B. Tumour in white light (patient 9)

from paraffin-embedded tissue. The MS-MLPA method is described in detail elsewhere [20]. Briefly, DNA was extracted from the fixed samples by the magnetic method using a Maxwell $^{\circ} 16$ FFPE Tissue LEV DNA Purification Kit (Promega, Madison, WI, USA). The MLPA method was validated prior to clinical use on 50 archival tissue samples, with methylation verified using pyrosequencing and methylation PCR. Codeletion was not verified using other methods because there is known to be a high correlation between MLPA and FISH test results [21-23].

MLPA is a comparative method, i.e. the result of a given test sample is compared to a control. According to the manufacturer's recommendations (MRC, Holland), for each experiment a minimum of four reference tests was used when the number of test samples did not exceed 20; when there were $>20$ tests performed, one reference sample was added for every seven tests in accordance with the manufacturer's recommendations. In addition, MLPA has a number of internal controls to assess each reaction and the purity and amount of DNA. The results were analysed using the dedicated coffalyser.net software (MRC, Holland). Repeatability and reproducibility were established as $100 \%$.

\section{Statistical analysis}

The results were described using descriptive statistics. Cohen's kappa coefficient and intraclass correlation coefficient (ICC) was used to assess the agreement between MSB and open biopsy molecular results (Statistica v 13.0).

\section{Results}

Of 531 patients with molecular results, only 11 (2.1\%) patients had molecular tests from both the MSB and subsequent surgery; five women (45.5\%) and six men (Table 1). The median age was 35 years (IQR 21-60 years). The initial KPS ranged from 60 to 100. After treatment, two patients experienced a deterioration in their quality of life.
Only one case had been biopsied and diagnosed as a glioma prior to surgery to determine the nature of the MRI changes. In this case, the MSB was performed to determine whether the visible lesion represented recurrence or necrosis after radiotherapy. In the MSBs, four (36.4\%) patients had WHO II astrocytoma diffusum, one patient $(9.1 \%)$ had oligodendroglioma, and the other six were classified as high-grade malignant gliomas. Of these, four (36.4\%) were diagnosed with anaplastic astrocytoma, and two (18.2\%) with glioblastoma multiforme. There were no other treatments between procedures, and the median interval between procedures was 57.5 days (16-132 days) (Tab. 1).

In all cases, the molecular tests were conclusive (Tab. 2). No perioperative complications were noted, and the neurological status did not change after MSB. After the procedure, each patient had a follow-up CT examination that did not reveal any bleeding. After surgery, the patients had a control MRI with contrast, which also showed no clinically significant incidents of bleeding.

A total absence of contrast-enhancing lesion or a contrastenhancing lesion with $<2 \%$ of the baseline change was considered to be a complete tumour resection. Contrast-enhancing lesions with a volume $>2 \%$ of the initial change were considered partial resections. In the post-surgery MRIs, total resection was demonstrated in seven (63.6\%) cases and partial resection in four cases (36.4\%) (Tab. 2). Two patients experienced a deterioration in neurological status accompanied by a deterioration in quality of life after craniotomy (18.2\%).

All histopathological findings after craniotomies were the same as the MSB results. The molecular results were also the same in all cases (absolute agreement of 1.00 ICC). MGMT promoter methylation was present in two patients, and $I D H$ mutations were present in seven cases (Cohen's kappa coefficient $1, \mathrm{p}<0.05$ ).

\section{Discussion}

Here we report that molecular genetics results derived from MSB are reliable and representative of both low- and 
Table 1. Clinicopathological features of the study population

$\begin{array}{lcc} & \text { Variable } & \text { Value } \\ \text { Age } & \text { Median 35 years (IQR 21-60 years) } \\ \text { Gender } & \text { Male } & 5(45.5 \%) \\ & 6(54.5 \%) & 7(63.6 \%) \\ \text { KPS before resection of a tumour } & 100 & 2(18.2 \%) \\ & 90 & 1(9.1 \%) \\ & 80 & 0(0 \%) \\ \text { KPS after resection of a tumour } & 70 & 1(9.1 \%) \\ & 60 & 6(54 \%) \\ \text { Performance status deterioration after surgery } & 100 & 2(18.2 \%) \\ \text { Histopathological diagnosis } & 90 & 0(0 \%) \\ \text { Interval between biopsy and resection } & 80 & 2(18.2 \%) \\ & 70 & 1(9.1 \%)\end{array}$

Table 2. Biopsy and surgery histopathology and molecular results of the entire group

\begin{tabular}{|c|c|c|c|c|c|c|c|}
\hline Number & $\begin{array}{l}\text { Histopathological } \\
\text { diagnosis (biopsy) }\end{array}$ & $\begin{array}{c}\text { Histopathological } \\
\text { diagnosis (craniotomy) }\end{array}$ & MGMT & IDH1 (R132) & $\begin{array}{l}\text { Deletion } \\
(1 p / 19 q)\end{array}$ & $\begin{array}{l}\text { Tumour } \\
\text { localisation }\end{array}$ & $\begin{array}{c}\text { Type } \\
\text { of } \\
\text { resection }\end{array}$ \\
\hline Patient 1 & $\begin{array}{l}\text { Astrocytoma anaplasticum } \\
\text { (WHO III) }\end{array}$ & $\begin{array}{l}\text { Astrocytoma anaplasticum } \\
\text { (WHO III) }\end{array}$ & - & Mutated & Negative & $\begin{array}{l}\text { Left frontal } \\
\text { lobe }\end{array}$ & Total \\
\hline Patient 2 & $\begin{array}{l}\text { Astrocytoma diffusum } \\
\text { (WHO II) }\end{array}$ & Astrocytoma diffusum (WHO II) & - & Mutated & Negative & $\begin{array}{l}\text { Right } \\
\text { temporal lobe }\end{array}$ & Total \\
\hline Patient 3 & $\begin{array}{l}\text { Astrocytoma AAASDADAS- } \\
\text { DADASDSDSADASDADDA- } \\
\text { strocytoma anaplasticum } \\
\text { (WHO III) }\end{array}$ & $\begin{array}{l}\text { AAASDADASDADASDSDSA- } \\
\text { DASDAstrocytoma anaplasti- } \\
\text { cum (WHO III) }\end{array}$ & - & No mutation & Negative & $\begin{array}{l}\text { Left } \\
\text { parietal lobe }\end{array}$ & Total \\
\hline Patient 4 & $\begin{array}{l}\text { Astrocytoma diffusum } \\
\text { (WHO II) }\end{array}$ & Astrocytoma diffusum (WHO II) & - & Mutated & Negative & $\begin{array}{l}\text { Right } \\
\text { insular lobe }\end{array}$ & Partial \\
\hline Patient 5 & $\begin{array}{l}\text { Astrocytoma diffusum } \\
\text { (WHO II) }\end{array}$ & Astrocytoma diffusum (WHO II) & - & No mutation & Negative & $\begin{array}{l}\text { Left cerebellar } \\
\text { lobe }\end{array}$ & Partial \\
\hline Patient 6 & Oligodendroglioma (WHO II) & Oligodendroglioma (WHO II) & - & No mutation & Positive & $\begin{array}{l}\text { Right frontal } \\
\text { lobe }\end{array}$ & Partial \\
\hline Patient 7 & $\begin{array}{l}\text { Astrocytoma anaplasticum } \\
\text { (WHO III) }\end{array}$ & $\begin{array}{l}\text { Astrocytoma anaplasticum } \\
\text { (WHO III) }\end{array}$ & - & No mutation & Negative & $\begin{array}{l}\text { Left temporal } \\
\text { lobe }\end{array}$ & Partial \\
\hline Patient 8 & $\begin{array}{l}\text { Astrocytoma diffusum } \\
\text { (WHO II) }\end{array}$ & Astrocytoma diffusum (WHO II) & - & Mutated & Negative & $\begin{array}{l}\text { Cerebellar } \\
\text { vermis }\end{array}$ & Total \\
\hline Patient 9 & $\begin{array}{l}\text { Glioblastoma multiforme } \\
\text { (WHO IV) }\end{array}$ & $\begin{array}{l}\text { Glioblastoma multiforme } \\
\text { (WHO IV) }\end{array}$ & $\begin{array}{l}\text { Meth- } \\
\text { ylated }\end{array}$ & Mutated & Negative & $\begin{array}{l}\text { Left frontal } \\
\text { lobe }\end{array}$ & Total \\
\hline Patient 10 & $\begin{array}{l}\text { Astrocytoma anaplasticum } \\
\text { (WHO III) }\end{array}$ & $\begin{array}{l}\text { Astrocytoma anaplasticum } \\
\text { (WHO III) }\end{array}$ & $\begin{array}{l}\text { Meth- } \\
\text { ylated }\end{array}$ & Mutated & Negative & $\begin{array}{l}\text { Left occipital } \\
\text { lobe }\end{array}$ & Total \\
\hline Patient 11 & $\begin{array}{l}\text { Glioblastoma multiforme } \\
\text { (WHO IV) }\end{array}$ & $\begin{array}{l}\text { Glioblastoma multiforme } \\
\text { (WHO IV) }\end{array}$ & & No mutation & Negative & $\begin{array}{l}\text { Right occipital } \\
\text { lobe }\end{array}$ & Total \\
\hline
\end{tabular}


high-grade gliomas. MLPA testing on stereotactic biopsy material and tissue derived after craniotomy appears to be equivalent for genetic analysis.

Molecular diagnostic testing should be considered whenever changes in tumour molecular biology might be expected, i.e. after primary therapy and where the results might justify the use of adjuvant systemic therapy. At the time of asymptomatic recurrence, the value of an open craniotomy should be balanced against the risk of complications and prolonging the time before starting systemic or radiation therapy [24-28]. Additionally, safe resection or macroscopic tumour removal is not feasible when gliomas are localised in eloquent areas. The role of subtotal surgery, especially in recurrent high-grade gliomas or previously unirradiated low-grade gliomas, remains unclear. It has been shown that subtotal tumour removal has no advantage over chemoradiation in the treatment of glioblastomas. Nevertheless, partial resections have generally been considered to be the only reliable method to obtain precise molecular results, and from this point of view our results are of great practical significance.

The simultaneous development of molecular diagnostics and the possibility of adopting effective conservative treatment in patients with low-grade gliomas with $I D H 1$ mutations encourages the use of MSB $[29,30]$. Our data suggests that it is reasonable to guide targeted therapies based on MSB results rather than open surgery. The most beneficial genetic alteration in gliomas is coexistent $I D H 1$ mutation and $M G M T$ promoter methylation [31]. Here, both IDH mutation and MGMT promoter methylation status established by MSB and surgery were conclusive, irrespective of tumour grade.

In a recent report, macroscopic gross total resection was achieved in approximately $80 \%$ of glioma cases [32]. In patients initially qualifying for stereotactic biopsy, complete surgical resection was more difficult, being achieved in $63.6 \%$ of cases, and as a consequence of preselection of patients for MSB in our department.

In this study, MS-MLPA was used due to its high reproducibility, accuracy, and robustness [20-23, 33]. MS-MLPA has a number of advantages over conventional MS-polymerase chain reaction (PCR) [20]. Regardless of the method used, it should be emphasised that MGMT promoter methylation may change over time $[34,35]$, which must be taken into account when there is a long gap between examinations.

Glioma heterogeneity has been evaluated in several studies [36-41]. Heterogeneous MGMT promoter methylation status has mainly been noted in high-grade tumours [ 42 , 43], raising concerns as to whether single MSB results are representative. Some studies have reported differences in the molecular and histopathological diagnosis in different samples from the same tumour, missing anaplastic foci in stereotactic samples [39, 44]. Furthermore, the phenomenon of pseudo-heterogeneity should be considered when there are large amounts of intratumoural necrosis, inflammation, or normal tissue in glioma samples. A recent study
[38] detected no MGMT promoter heterogeneity between different samples taken from the same tumours in 24 out of 25 patients; the one false negative that was detected was due to DNA dispersing into necrotic tissues. This is consistent with our results and the results of a serial MSB study into WHO II gliomas, where MGMT methylation and IDH mutations were homogeneous inside and outside hotspots of all 14 tumours tested [44].

A recent comparison of biopsy and surgery molecular results [45] reported similar results to ours, the main differences being the histopathological diagnosis and molecular diagnostic test (MS-PCR) chosen [16]. Gessler et al. [45] did not examine low-grade gliomas, the group instead being limited to three anaplastic astrocytomas and 19 glioblastomas. In both studies, samples were examined after a short interval, mainly due to the non-specific radiological appearances. Conclusive molecular biomarkers were obtained from small biopsy samples $\left(<1 \mathrm{~mm}^{3}\right)$ by selecting many probes and by using a highly controlled sampling technique, with intraoperative neuropathological examination to exclude any contamination. Eigenbrod et al. [16] collected at least two samples from different tumour sites to determine MGMT promoter methylation, while we showed that the results are the same in samples obtained by biopsy and open craniotomy. We also showed that MSB is effective in both low- and highgrade gliomas.

Many papers have reported the safety and diagnostic value of materials obtained using stereotactic biopsy [46-50]. The number of perioperative complications occurring during surgical resections of brain tumours remains significant [51]. Even in our neurosurgery department, a facility with a high level of experience, the performance status decreased in two out of 11 patients.

Our study is limited by the small number of cases analysed; however, this also meant that of 531 biopsies, only 11 had clinical indications for subsequent open surgery. This uncommon scenario is also reflected in the number of patients recruited in other series [45]. It should be noted that the proportion of normal, non-tumour cells and neoplastic cells may falsely influence the MGMT methylation result in MS-MLPA. Moreover, there was an almost two month gap between MSB and open craniotomy in some cases, although histopathological and molecular results did not change depite this interval.

\section{Clinical implications/future directions}

Given our small group, cautious conclusions should be drawn. However, we have shown that the material obtained for MSB from both low- and high-grade gliomas can be used for the precise assessment of molecular status, and that MSB provides material for the valid and reproducible examination for multiple biomarkers without compromising the quality of histological classification and grading. MSB can be used for definitive molecular diagnosis and represents the final stage 
of neurosurgical activities in some cases, especially tumours in which there is little chance of total removal without consequential neurological deficits. Further large-scale concordance studies are required to further validate molecular diagnoses on MSB specimens.

Acknowledgements: Nextgenediting (www.nextgenediting. com) for editorial assistance. Sincere gratitude to Tadeusz Szylberg, the Head of Department of Pathology, and Krystyna Soszynska, the Head of Laboratory of Clinical Genetics and Molecular Pathology, $10^{\text {th }}$ Military Research Hospital, for kind cooperation in biopsies and performing the histopathological and molecular studies.

\section{References}

1. Fisher J, Schwartzbaum J, Wrensch M, et al. Epidemiology of Brain Tumors. Neurologic Clinics. 2007; 25(4): 867-890, doi: 10.1016/j. ncl.2007.07.002.

2. Louis DN, Ohgaki H, Wiestler OD, et al. The 2007 WHO classification of tumours of the central nervous system. Acta Neuropathol. 2007; 114(2): 97-109, doi: 10.1007/s00401-007-0243-4, indexed in Pubmed: 17618441.

3. Ostrom QT, Gittleman H, Truitt G, et al. CBTRUS Statistical Report: Primary Brain and Other Central Nervous System Tumors Diagnosed in the United States in 2011-2015. Neuro Oncol. 2018; 20 (suppl_4): iv1-iv86, doi: 10.1093/neuonc/noy131, indexed in Pubmed: 30445539.

4. Sathornsumetee S, Rich JN, Reardon DA. Diagnosis and treatment of high-grade astrocytoma. Neurol Clin. 2007; 25(4): 1111-1139, x, doi: 10.1016/j.ncl.2007.07.004, indexed in Pubmed: 17964028.

5. Weller M, Pfister SM, Wick W, et al. Molecular neuro-oncology in clinical practice: a new horizon. Lancet Oncol. 2013; 14(9): e370e379, doi: 10.1016/S1470-2045(13)70168-2, indexed in Pubmed: 23896276.

6. Wen PY, Kesari S. Malignant gliomas in adults. N Engl J Med. 2008; 359(5): 492-507, doi: 10.1056/NEJMra0708126, indexed in Pubmed: 18669428.

7. Brat DJ, Verhaak RGW, Aldape KD, et al. Cancer Genome Atlas Research Network. Comprehensive, Integrative Genomic Analysis of Diffuse Lower-Grade Gliomas. N Engl J Med. 2015; 372(26): 2481-2498, doi: 10.1056/NEJMoa1402121, indexed in Pubmed: 26061751.

8. Dubbink HJ, Atmodimedjo PN, Kros JM, et al. Molecular classification of anaplastic oligodendroglioma using next-generation sequencing: a report of the prospective randomized EORTC Brain Tumor Group 26951 phase III trial. Neuro Oncol. 2016; 18(3): 388-400, doi: 10.1093/neuonc/nov182, indexed in Pubmed: 26354927.

9. Eckel-Passow JE, Lachance DH, Molinaro AM, et al. Glioma Groups Based on 1p/19q, IDH, and TERT Promoter Mutations in Tumors. N Engl J Med. 2015; 372(26): 2499-2508, doi: 10.1056/NEJMoa1407279, indexed in Pubmed: 26061753.

10. Hegi ME, Stupp R. Withholding temozolomide in glioblastoma patients with unmethylated MGMT promoter-still a dilemma? Neuro Oncol. 2015; 17(11): 1425-1427, doi: 10.1093/neuonc/nov198, indexed in Pubmed: 26374690.

11. Goldstein ED, Feyissa AM. Brain tumor related-epilepsy. Neurol Neurochir Pol. 2018; 52(4): 436-447, doi: 10.1016/j.pjnns.2018.06.001, indexed in Pubmed: 30122210.
12. Horbinski C. What do we know about IDH1/2 mutations so far, and how do we use it? Acta Neuropathol. 2013; 125(5): 621-636, doi: 10.1007/s00401-013-1106-9, indexed in Pubmed: 23512379.

13. Hartmann C, Mueller W, Lass U, et al. Molecular genetic analysis of oligodendroglial tumors. J Neuropathol Exp Neurol. 2005; 64(1): 10-14, doi: 10.1093/jnen/64.1.10, indexed in Pubmed: 15715080.

14. Okamoto Y, Di Patre PL, Burkhard C, et al. Population-based study on incidence, survival rates, and genetic alterations of low-grade diffuse astrocytomas and oligodendrogliomas. Acta Neuropathol. 2004; 108(1): 49-56, doi: 10.1007/s00401-004-0861-z, indexed in Pubmed: 15118874.

15. Appin CL, Gao J, Chisolm C, et al. Glioblastoma with oligodendroglioma component (GBM-0): molecular genetic and clinical characteristics. Brain Pathol. 2013; 23(4): 454-461, doi: 10.1111/bpa.12018, indexed in Pubmed: 23289977.

16. Eigenbrod S, Trabold R, Brucker D, et al. Molecular stereotactic biopsy technique improves diagnostic accuracy and enables personalized treatment strategies in glioma patients. Acta Neurochir (Wien). 2014; 156(8): 1427-1440, doi: 10.1007/s00701-014-2073-1, indexed in Pubmed: 24792966.

17. luchi $\mathrm{T}$, Namba $\mathrm{H}$, Iwadate $\mathrm{Y}$, et al. Identification of the small interstitial deletion at chromosome band 1p34-p35 and its association with poor outcome in oligodendroglial tumors. Genes Chromosomes Cancer. 2002; 35(2): 170-175, doi: 10.1002/gcc.10080, indexed in Pubmed: 12203781.

18. Louis D, Ohgaki H, Wiestler O, et al. The 2007 WHO classification of tumours of the central nervous system. Acta Neuropathologica. 2007; 114(5): 547-547, doi: 10.1007/s00401-007-0278-6.

19. Weise LM, Harter PN, Eibach S, et al. Confounding factors in diagnostics of MGMT promoter methylation status in glioblastomas in stereotactic biopsies. Stereotact Funct Neurosurg. 2014; 92(3): 129-139, doi: 10.1159/000360582, indexed in Pubmed: 24776650.

20. Jeuken JWM, Cornelissen SJB, Vriezen M, et al. MS-MLPA: an attractive alternative laboratory assay for robust, reliable, and semiquantitative detection of MGMT promoter hypermethylation in gliomas. Lab Invest. 2007; 87(10): 1055-1065, doi: 10.1038/labinvest.3700664, indexed in Pubmed: 17700563.

21. Franco-Hernández $\mathrm{C}$, Martínez-Glez V, de Campos JM, et al. Allelic status of $1 p$ and $19 q$ in oligodendrogliomas and glioblastomas: multiplex ligation-dependent probe amplification versus loss of heterozygosity. Cancer Genet Cytogenet. 2009; 190(2): 93-96, doi: 10.1016/j.cancergencyto.2008.09.017, indexed in Pubmed: 19380026.

22. Natté R, Eijk R, Eilers $P$, et al. Multiplex Ligation-Dependent Probe Amplification for the Detection of $1 p$ and 19q Chromosomal Loss in Oligodendroglial Tumors. Brain Pathology. 2006; 15(3): 192-197, doi: 10.1111/j.1750-3639.2005.tb00520.x.

23. Woehrer A, Hainfellner JA. Molecular diagnostics: techniques and recommendations for 1p/19q assessment. CNS Oncol. 2015; 4(5): 295-306, doi: 10.2217/cns.15.28, indexed in Pubmed: 26545171.

24. Gessler F, Forster MT, Duetzmann S, et al. Combination of Intraoperative Magnetic Resonance Imaging and Intraoperative Fluorescence to Enhance the Resection of Contrast Enhancing Gliomas. Neurosurgery. 2015; 77(1): 16-22; discussion 22, doi: 10.1227/ NEU.0000000000000729, indexed in Pubmed: 25812066.

25. Lacroix M, Abi-Said D, Fourney DR, et al. A multivariate analysis of 416 patients with glioblastoma multiforme: prognosis, extent of resection, and survival. J Neurosurg. 2001; 95(2): 190-198, doi: 10.3171/ jns.2001.95.2.0190, indexed in Pubmed: 11780887. 
26. Ringel F, Pape H, Sabel M, et al. SN1 study group. Clinical benefit from resection of recurrent glioblastomas: results of a multicenter study including 503 patients with recurrent glioblastomas undergoing surgical resection. Neuro Oncol. 2016; 18(1): 96-104, doi: 10.1093/neuonc/ nov145, indexed in Pubmed: 26243790.

27. Sanai N, Polley MY, McDermott MW, et al. An extent of resection threshold for newly diagnosed glioblastomas. J Neurosurg. 2011; 115(1): 3-8, doi: 10.3171/2011.2.jns10998, indexed in Pubmed: 21417701.

28. Stupp R, Mason WP, van den Bent MJ, et al. European Organisation for Research and Treatment of Cancer Brain Tumor and Radiotherapy Groups, National Cancer Institute of Canada Clinical Trials Group. Radiotherapy plus concomitant and adjuvant temozolomide for glioblastoma. N Engl J Med. 2005; 352(10): 987-996, doi: 10.1056/ NEJMoa043330, indexed in Pubmed: 15758009.

29. Nobusawa S, Watanabe T, Kleihues P, et al. IDH1 mutations as molecular signature and predictive factor of secondary glioblastomas. Clin Cancer Res. 2009; 15(19): 6002-6007, doi: 10.1158/1078-0432. CCR-09-0715, indexed in Pubmed: 19755387.

30. Schumacher T, Bunse L, Pusch S, et al. A vaccine targeting mutant IDH1 induces antitumour immunity. Nature. 2014; 512(7514): 324327, doi: 10.1038/nature13387, indexed in Pubmed: 25043048.

31. Molenaar RJ, Verbaan D, Lamba S, et al. The combination of IDH1 mutations and MGMT methylation status predicts survival in glioblastoma better than either IDH1 or MGMT alone. Neuro Oncol. 2014; 16(9): 1263-1273, doi: 10.1093/neuonc/nou005, indexed in Pubmed: 24510240.

32. Catapano G, Sgulò FG, Seneca V, et al. Fluorescein-Guided Surgery for High-Grade Glioma Resection: An Intraoperative "Contrast-Enhancer“. World Neurosurg. 2017; 104: 239-247, doi: 10.1016/j. wneu.2017.05.022, indexed in Pubmed: 28512039.

33. Bieńkowski M, Wöhrer A, Moser $P$, et al. Molecular diagnostic testing of diffuse gliomas in the real-life setting: A practical approach. Clin Neuropathol. 2018; 37(4): 166-177, doi: 10.5414/NP301110, indexed in Pubmed: 29923492.

34. Harat M, Blok M, Harat A, et al. The impact of adjuvant radiotherapy on molecular prognostic markers in gliomas. Onco Targets Ther. 2019; 12: 2215-2224, doi: 10.2147/0TT.S200818, indexed in Pubmed: 30988626.

35. Park CK, Kim JaE, Kim JiY, et al. The Changes in MGMT Promoter Methylation Status in Initial and Recurrent Glioblastomas. Transl Oncol. 2012; 5(5): 393-397, doi: 10.1593/tlo.12253, indexed in Pubmed: 23066447.

36. Barresi V, Caffo M, Luca GDe, et al. 0-6-methylguanine-DNA methyltransferase promoter methylation can change in glioblastoma recurrence due to intratumor heterogeneity. Glioma. 2018; 1(6): 208, doi: 10.4103/glioma.glioma_38_18.

37. Eskilsson E, Rosland GV, Talasila KM, et al. EGFRvill mutations can emerge as late and heterogenous events in glioblastoma development and promote angiogenesis through Src activation. Neuro Oncol. 2016; 18(12): 1644-1655, doi: 10.1093/neuonc/now113, indexed in Pubmed: 27286795.

38. Grasbon-Frodl EM, Kreth FW, Ruiter M, et al. Intratumoral homogeneity of MGMT promoter hypermethylation as demonstrated in serial stereotactic specimens from anaplastic astrocytomas and glioblastomas. Int J Cancer. 2007; 121(11): 2458-2464, doi: 10.1002/ijc.23020, indexed in Pubmed: 17691113.
39. Patel AP, Tirosh I, Trombetta JJ, et al. Single-cell RNA-seq highlights intratumoral heterogeneity in primary glioblastoma. Science. 2014; 344(6190): 1396-1401, doi: 10.1126/science.1254257, indexed in Pubmed: 24925914.

40. Sciuscio D, Diserens AC, van Dommelen $\mathrm{K}$, et al. Extent and patterns of MGMT promoter methylation in glioblastoma- and respective glioblastoma-derived spheres. Clin Cancer Res. 2011; 17(2): $255-$ 266, doi: 10.1158/1078-0432.CCR-10-1931, indexed in Pubmed: 21097691.

41. Sottoriva A, Kang H, Ma Z, et al. A Big Bang model of human colorectal tumor growth. Nat Genet. 2015; 47(3): 209-216, doi: 10.1038/ ng.3214, indexed in Pubmed: 25665006.

42. Parker NR, Hudson AL, Khong P, et al. Intratumoral heterogeneity identified at the epigenetic, genetic and transcriptional level in glioblastoma. Sci Rep. 2016; 6: 22477, doi: 10.1038/srep22477, indexed in Pubmed: 26940435.

43. Parkinson JF, Wheeler HR, Clarkson A, et al. Variation of O(6)-methyIguanine-DNA methyltransferase (MGMT) promoter methylation in serial samples in glioblastoma. J Neurooncol. 2008; 87(1): 71-78, doi: 10.1007/s11060-007-9486-0, indexed in Pubmed: 18004504.

44. Kunz M, Thon N, Eigenbrod S, et al. Hot spots in dynamic (18)FET-PET delineate malignant tumor parts within suspected WHO grade II gliomas. Neuro Oncol. 2011; 13(3): 307-316, doi: 10.1093/neuonc/ noq196, indexed in Pubmed: 21292686.

45. Gessler F, Baumgarten P, Bernstock JD, et al. Assessment of molecular markers demonstrates concordance between samples acquired via stereotactic biopsy and open craniotomy in both anaplastic astrocytomas and glioblastomas. J Neurooncol. 2017; 133(2): 399-407, doi: 10.1007/s11060-017-2448-2, indexed in Pubmed: 28508327.

46. Aker F, Hakan T, Karadereler S, et al. Accuracy and diagnostic yield of stereotactic biopsy in the diagnosis of brain masses: Comparison of results of biopsy and resected surgical specimens. Neuropathology. 2005; 25(3): 207-213, doi: 10.1111/j.1440-1789.2005.00634.x.

47. Jain D, Sharma MC, Sarkar C, et al. Correlation of diagnostic yield of stereotactic brain biopsy with number of biopsy bits and site of the lesion. Brain Tumor Pathol. 2006; 23(2): 71-75, doi: 10.1007/ s10014-006-0204-y, indexed in Pubmed: 18095122.

48. Shastri-Hurst N, Tsegaye M, Robson DK, et al. Stereotactic brain biopsy: An audit of sampling reliability in a clinical case series. Br J Neurosurg. 2006; 20(4): 222-226, doi: 10.1080/02688690600875507, indexed in Pubmed: 16954072.

49. Smith JS, Quiñones-Hinojosa A, Barbaro NM, et al. Frame-based stereotactic biopsy remains an important diagnostic tool with distinct advantages over frameless stereotactic biopsy. J Neurooncol. 2005; 73(2): 173-179, doi: 10.1007/s11060-004-4208-3, indexed in Pubmed: 15981109.

50. Weise LM, Bruder M, Eibach S, et al. Efficacy and safety of local versus general anesthesia in stereotactic biopsies: a matched-pairs cohort study. J Neurosurg Anesthesiol. 2013; 25(2): 148-153, doi: 10.1097/ ANA.0b013e318274ce41, indexed in Pubmed: 23103527.

51. Gessler F, Bruder M, Duetzmann S, et al. Risk factors governing the development of cerebral vein and dural sinus thrombosis after craniotomy in patients with intracranial tumors. J Neurosurg. 2018; 128(2): 373-379, doi: 10.3171/2016.11.JNS161871, indexed in Pubmed: 28387630 . 